\title{
Social and Economic Impact of School Closure during the Outbreak of the COVID-19 Pandemic: A Quick Online Survey in the Gaza Strip
}

\author{
Afnan Radwan ${ }^{1,2}$, Eqbal Radwan ${ }^{3,4^{*}}$
}

\author{
${ }^{1}$ Faculty of Education, Islamic University of Gaza, Gaza Strip, PALESTINE \\ ${ }^{2}$ Rafah Elementary E Boys School, South Rafah Educational Region, UNRWA, PALESTINE \\ ${ }^{3}$ Biology Department, Faculty of Science, Islamic University of Gaza, PALESTINE \\ ${ }^{4}$ Directorate of Education-East Gaza, Ministry of Education and Higher Education, PALESTINE \\ *Corresponding Author: ernp2030@gmail.com
}

Citation: Radwan, A., \& Radwan, E. (2020). Social and Economic Impact of School Closure during the Outbreak of the COVID-19 Pandemic: A Quick Online Survey in the Gaza Strip. Pedagogical Research, 5(4), em0068. https://doi.org/10.29333/pr/8254

\begin{abstract}
ARTICLE INFO
Received: 1 May. 2020

Accepted: 5 May. 2020

ABSTRACT

In response to the coronavirus disease 2019 (COVID-19) pandemic, many countries had implemented school closures by March 6, 2020. This study aimed to evaluate the social and economic impact of school closure on the students' families. Households were surveyed using an online questionnaire interview to obtain information on adherence to, socio-economic impact by and inconveniences of school closure. The current study showed that school closures have profound economic and social consequences in the Gaza Strip. Most of the interviewed households (88.1\%) were supportive of the school closure, whereas only $11.9 \%$ did not support it. Despite the restriction on attending gatherings or visiting public places, $30.5 \%$ of the school student visited relatives, $8.5 \%$ went to public places, and $3.4 \%$ went to parents' workplaces. Overall, $25.4 \%$ of the interviewed households reported workplace absenteeism, whereas the highest percentage $(74.6 \%)$ were not absenteeism from their work. The economic harms of school closures are high, where $77.9 \%$ of households reported their wage loss during the closure. The daily wage lost per household ranged from 3 to 265 ILS.
\end{abstract}

Keywords: COVID-19 pandemic, school closure, transmission, absenteeism, Gaza Strip

\section{INTRODUCTION}

A novel coronavirus (hereafter COVID-19 for COronaVIrus Disease 19) was reported to the World Health Organization (WHO) in the South China seafood market in Wuhan, Hubei Province, China on 31 December 2019. The number of patients with coronavirus has extensively skyrocketed throughout the world. The daily updates suggest the confirmed global cases detected currently stand at 3,181,642, with 224,301 deaths, as of 2 May 2020 (World Health Organization, 2020). These numbers are likely to have increased substantially well after this paper is published. As COVID-19 pandemic emerged in December 2019, the World Health Organization (WHO) stated that there was a 'public health emergency of international concern, and raised pandemic level to highest level in February 2020.

Many schools were temporarily closed in response to outbreaks of the recently emerged pandemic COVID-19. In a COVID-19 pandemic, students are effective in spreading the virus, and schools' closure are considered the first intervention for implementation (Viner et al., 2020). During the coronavirus epidemic around the world, timely school closure and cancellation of public gatherings were significantly associated with reduced infection related to the COVID-19 epidemics. More recently, it was reported that the 2019-nCoV spreads rapidly and has posed a severe threat to public health (Han et al., 2020), which necessitates the need to reduce friction and communication between students. Furthermore, mathematical modeling studies have revealed that school closure could have significant effects on the epidemic size and on mitigating the local progression of the pandemics (Ferguson et al., 2006, Germann et al., 2006). On the other hand, school closure is costly; gross domestic product (GDP) has lost by a certain percent varied among countries. Therefore, the implementation of such a policy should be weighed against economic and social impact during the COVID-19 epidemic.

In Palestine, the COVID-19 pandemic was confirmed to have spread to the West Bank on 5 March 2020, beginning the 2020 COVID-19 outbreak. Later, the first two cases in the Gaza Strip were diagnosed on 21 March. As of 2 May 2020, the number of confirmed patients was 517, where 76 cases have recovered (Ministry of Health, 2020).

To help contain the spread of the coronavirus and prevent a possible large scale outbreak among students, the Ministry of Education and Higher Education has decided to close all educational institutions temporarily from March 6, 2020, until further notice. The parents were instructed to keep their children at home while the school was closed, and prohibited them from visiting 
public places or attend gatherings. The school teachers were to provide tutoring over the social media while classes were suspended so that students would not fall behind with their school work. Because COVID-19-related school closure had done in the Gaza Strip, we evaluated the social and economic impact of school closure on the students' families.

In the current study, the author follows the same methodology which was previously applied by Chen et al. (2011) in the case of pandemic influenza $\mathrm{A} / \mathrm{H} 1 \mathrm{~N} 1$.

\section{METHODOLOGY}

\section{Study Setting (Outbreak Response)}

In response to the coronavirus disease 2019 (COVID-19) pandemic, our country had implemented school closures, affecting 1.3 million children and young people aged from 3 years to 17 years. During the movement restrictions period, the parents were instructed to keep children at home while the school was closed, and children were prohibited from visiting public places or attend gatherings. Primary and secondary school teachers were to provide tutoring over the social media while classes were suspended so that students would not fall behind with their school work.

The current study was conducted from March 10 to April 13, the week immediately after the lockdown of the educational institutions including the public, private and UNRWA schools. Because it was not feasible to do a community-based national sampling survey during this critical period, we decided to collect the data during the online interview. Relying on the authors' networks with the students, the poster was posted on the groups of WhatsApp and Facebook accounts. This poster contained a brief introduction, objective, declarations of anonymity and confidentiality, and notes for complete the interview. Households who agreed to participate in the study were instructed to complete the interview via social media.

\section{Questionnaire Interview (Assessment of Impact)}

Because it was not possible to carry out a community-based sampling survey during this critical period, we decided to collect the data online. To evaluate household response to school closure, an online interview of students household was conducted during the quarantine period. The interview assessed adherence to restrictions on public place visits or gatherings during the closure and evaluated the economic impact of workplace absenteeism and associated wage loss during school closure.

The interviewed households were asked about their attitudes toward school closure and the main cause of inconveniences by the closure. Finally, to assess the impact on the school staff, the school principal was interviewed and provided information on the additional workload on the teachers during school closure.

\section{Sample Size}

Concerning sample size, the estimation was done by using the equation of probability and confidence interval. Viechtbauer et al. (2015), described a simple method for choosing a sample size for a pilot study that ensures the discovery of potential problems with high confidence. For our calculations, the confidence level is set at 95\%, meaning that a $5 \%$ significance level is set. According to Viechtbauer et al. (2015), the equation for sample size sampling is expressed in Equation (1):

$$
n=\ln (1-\gamma) / \ln (1-\pi)
$$

Where $n$ denotes the number of participants, $\gamma$ denotes probability (0.05), and $\pi$ denotes confidence level (95\%). In the present study, for $\pi=0.05$ probability, required the inclusion of $n=\ln (1-0.95) / \ln (1-0.05)=58.40$, or rather 59 participants in the pilot study, so that the problem was detected with a high confidence level.

\section{Statistical Analysis}

Epi-Info ${ }^{\mathrm{TM}}$ Version 7.2 was applied for data entry. Descriptive analyses were carried out by calculating frequencies and percentages for interesting variables.

\section{RESULTS}

\section{Impact of School Closure on the Students' Families}

Of the 59 households, $53(89.8 \%)$ were parents, 4 (6.8\%) were grandparents, and $2(3.4 \%)$ were other relatives. The current study revealed that most of the interviewed households 52 (88.1\%) were supportive of the school closure, whereas only 7 (11.9\%) did not support this procedure. The respondents who support the closure mentioned that schools closing were applied as a preventive measure to ensure the safety of students and their families and to prevent or reduce risks, if its present, of COVID-19 infection. Besides, they reported that the closure of schools is a proposed strategy for reducing COVID-19 transmission and finding an alternative to quarantine places, where there are no places specialized for emergency circumstances including an outbreak of the pandemics. On the other hand, a few percents of the interviewed households were not supportive of the school closure due to different reasons (Figure 1). The most common inconveniences among those who did not support the closure were lost wages. The present study showed that $28.5 \%$ of the interviewed respondents very concerned about the students' return to school and resuming their educational duties, where their educational performance was affected as a result of school closure. 


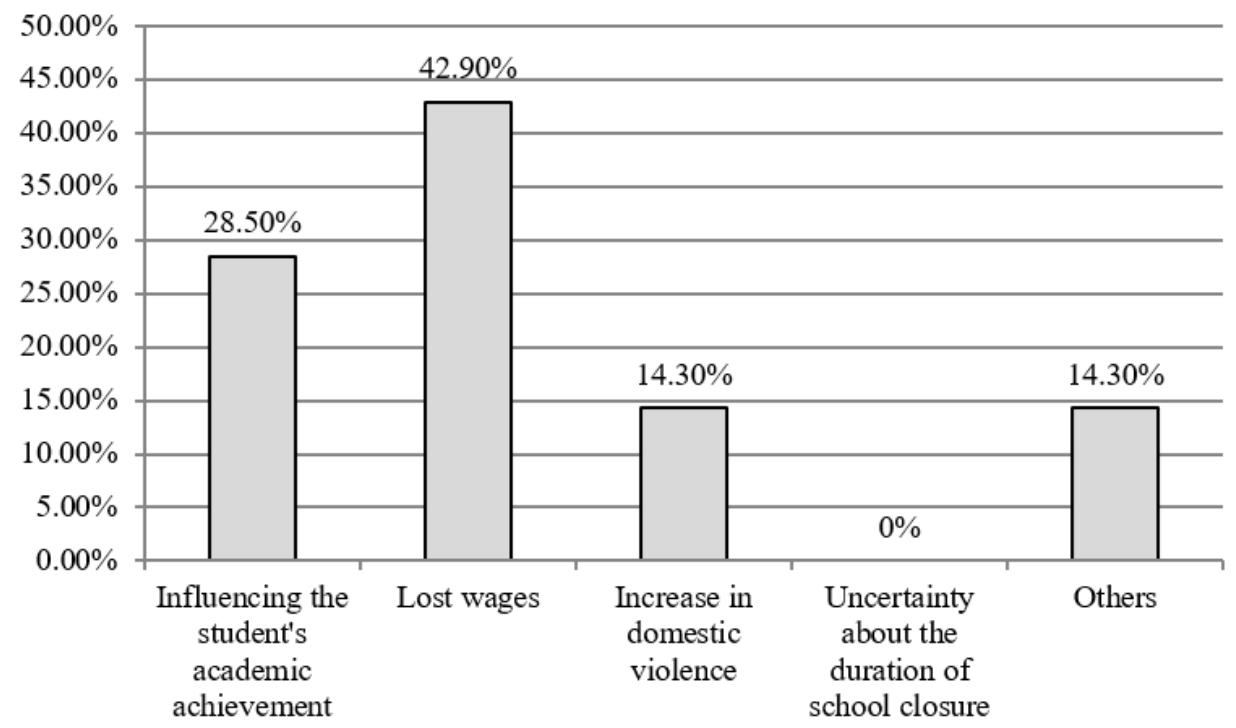

Figure 1. The most common inconveniences caused by school closure for households of students

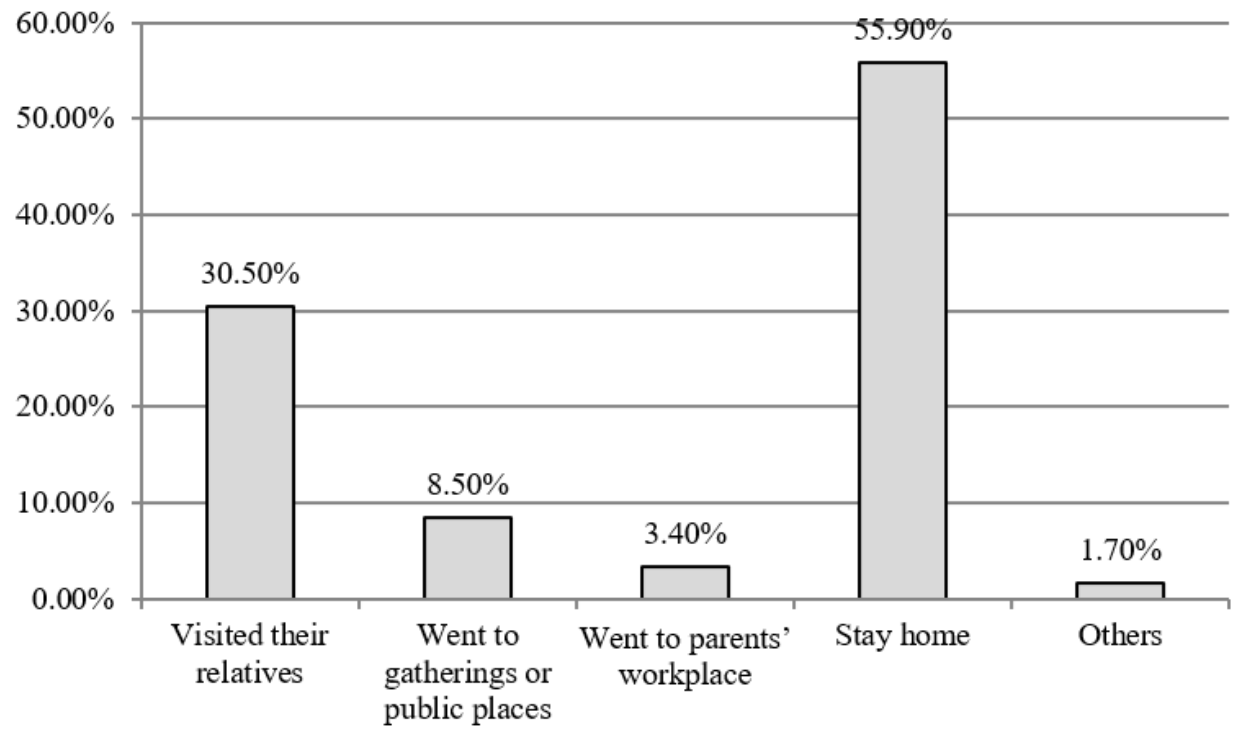

Figure 2. Student's activities during the movement restrictions period

Table 1. Distribution of the interviewed households according to wage loss (\%)

\begin{tabular}{ccccccc}
\hline & \multicolumn{3}{c}{$\begin{array}{c}\text { Absenteeism from work } \\
\mathbf{1 5}(\mathbf{2 5 . 4 \% )}\end{array}$} & & \multicolumn{3}{c}{ Not absenteeism from work } \\
$\mathbf{4 4}(\mathbf{7 4 . 6 \% )}$
\end{tabular}

Despite the restriction on attending gatherings or visiting public places, $30.5 \%$ of the school student visited relatives, $8.5 \%$ went to gatherings or public places at least once, 3.4\% went to parents' workplaces (Figure 2). The majority of the interviewed respondents (55.9\%) stay home and did not go out of their homes except in the case of extreme necessity.

The present study revealed that $25.4 \%$ of the interviewed households reported workplace absenteeism, whereas the highest percentage (74.6\%) were not absenteeism from their work. The absenteeism participants were found to work neither permanently (They receive a salary monthly) or temporarily (daily paid, thus they receive a salary depending on the number of worked days) in the governmental places, private sector or other places.

The results of this study showed that the economic harms of school closures are high, where the majority of households (77.9\%) reported their wage loss during the closure (Table 1). Of these, only $23 \%$ of them specified the duration of working days lost, totaling 38 days till 13 April 2020 (range, 1- 38 days). The respondents reported that the daily wage lost per household ranged 
from 3 to 265 ILS. During 2019, the average daily wage in Gaza was only 6.5 ILS (approx. 2 USD) per day. This daily income is considered the worst in the world.

\section{Impact of School Closure on the School Staff}

On Friday night, March 6, all educational staff and students were informed about school closure until further notice. The Ministry of Education announced the implementation of an emergency plan to face the unexpected closure of the Schools. The Ministry's team has started to prepare, record, and broadcast the educational lessons on the radio (Voice of Education, live audio, 102.7 FM) and through live broadcasts on Facebook. In addition, a significant number of teachers have uploaded educational materials, worksheets, and supporting files on the Ministry's website to give students an opportunity to download it and benefit from them. Some teachers made individual efforts, as they created a group on WhatsApp or Facebook to supplement the curriculum explanation. During the closure, teachers and staff continued their assigned duties. Also, homeroom teachers have contacted the students in his/her class by phone or social media, to monitor their students' health and ensure that they are staying indoors, and continuing with their school work. Meanwhile, some of the administrative staff took turns attending to other administrative duties.

\section{DISCUSSION}

In response to the COVID-19 pandemic, the ministry of health implemented containment policies that included quarantine, enhanced surveillance, patient isolation, contact tracing, and school closure from March 2020 till now. This is the first time in our country that all schools were closed during our containment phase of the outbreak of COVID-19 pandemic, which provided a unique opportunity to assess the influence of school closure on the stakeholders.

The present study revealed $88.1 \%$ of households supported the school closure, where a high degree of COVID-19 transmission may occur in schools and sustained school closure may reduce the spread of epidemic COVID-19, thereby reducing morbidity and mortality. Also, the respondents accepted the closure of schools to use it as a quarantine place. Meanwhile, On March 15, the Ministry of Health began turning two schools in Rafah city into quarantine centers where those entering Gaza Strip are placed as a precautionary measure against spreading the coronavirus. Such a measure is very important where the ministry of health had no other choice due to the deteriorating living conditions in the Gaza Strip. About 15 schools are serving as quarantine centers and in the current days, the Ministry of Health is preparing more schools for those arriving into Gaza Strip.

On the other hand, the study revealed that there were $11.9 \%$ of the participants were not supportive of the emergency closure of schools. According to Effler et al. (2010), they found out that $33 \%$ of the household felt that the closure of the school was not appropriate because of the disease was mild rather than a personal inconvenience. These households thought the school closure was inappropriate due to several reasons. They reported that movement restrictions may be making violence in homes more frequent, more severe and more dangerous. Movement limits have forced people to spend much more time at home, leading to a surge in domestic abuse cases. More recently, the World Health Organization (WHO) has warned that quarantine measures and stay-at-home during the COVID-19 pandemic will likely lead to a rise in the rates of domestic violence. In particular, the women and their children are more likely to be subjected to violence as family members spend more time with each other, where families cope with additional stress and potential economic.

Despite the restriction, $44.1 \%$ of the school student left their homes and did not stay home during the closure of the school. Previously, some studies assessed adherence to school closure in the time of the outbreak of various pandemics. For example, in Perth, Western Australia, 74\% of the students participated in different activities outside the home (Effler et al., 2010). In our survey, the adherence to the "stay home" policy appeared to be an acceptable level. This might have been related to the uncertainties in COVID-19 pandemic severity and exaggerated reporting of associated fatalities reported by the mass media at present. In our country, there is significant attention regarding increase the people's awareness of COVID-19 related issues.

In the current investigation, the majority of Palestinian households reported workplace absenteeism, wage loss and the need to pay for living requirements. Similar results were previously documented in a survey carried out in the United States, schools were closed during the outbreak of an influenza B; it was reported that $24 \%$ of the households had missed work, and $1 \%$ had to spend extra money for childcare during the school closure (Johnson et al., 2008). In the Gaza Strip, the economic costs and potential harms of school closure are undoubtedly very high, where $77.9 \%$ reported their wage loss during this closure. A study has been conducted in the USA (Keogh-Brown et al., 2010) showed that the closure of schools increased the economic cost to the nation. In the United Kingdom, a study showed that approximately $16 \%$ of the workforce is likely to be absent due to school closures in the time of the pandemic. This percent rises for sectors with a high percentage of female employees including health and social care (Sadique et al., 2008).

To sum up, this study shows that school closures have profound economic and social consequences in the Gaza Strip. This closure was implemented during the containment phase of the COVID-19 pandemic. With the efforts of the ministry of education, school staff and teachers to ensure the continued teaching and monitoring of the health of the students, this closure was supported by the majority of families, and wage loss incurred during the school closure contributed to the inconvenience of the interviewed households where the economic costs and potential harms of school closure are undoubtedly very high. Our results are useful for the future design of social and economic policies and to design modeling studies to accurately predict the impact of COVID-19 pandemic in the future on Palestinian society. Also, the results of the current study will be highly recommended to study the impact of schools closure not only from socioeconomic view, but also from educational view, where this crisis highly influenced on the educational system, and employing the digital technology must be taken into consideration to maintain learning 
of students (Basilaia \& Kvavadze, 2020; Mulenga \& Marbán, 2020; Toquero, 2020). Although the potential benefits of school closure might appear to be large, in terms of reducing social contacts between students and therefore interrupt the transmission, the economic costs of this closure must be taken into consideration by policymakers as soon as possible.

There are various limitations of the present study as follows:

- We did not evaluate the staff of public health contributed during the school closure.

- Prolonged school closure and increased wage loss might influence the overall attitude of households towards the policy of school closure and economic impact.

- In the current survey, we did not evaluate for symptoms of COVID-19 like illness among students or their contacts, where no cases were detected until now among students in the Gaza Strip. The infected cases were only detected in persons who come from abroad. Therefore, the effectiveness of school closure for disease containment was not ascertained. However, through the experience from different countries like Japan, during the outbreak of the influenza pandemic, it is reported that school closure has done early in the outbreak has a substantial effect on the mitigation of disease transmission (Kawaguchi et al., 2009).

\section{REFERENCES}

Basilaia, G., \& Kvavadze, D. (2020). Transition to Online Education in Schools during a SARS-CoV-2 Coronavirus (COVID-19) Pandemic in Georgia. Pedagogical Research, 5(4), em0060. https://doi.org/10.29333/pr/7937

Chen, W. C., Huang, A. S., Chuang, J. H., Chiu, C. C., \& Kuo, H. S. (2011). Social and economic impact of school closure resulting from pandemic influenza A/H1N1. Journal of Infection, 62(3), 200-203. https://doi.org/10.1016/j.jinf.2011.01.007

Effler, P. V., Carcione, D., Giele, C., Dowse, G. K., Goggin, L., \& Mak, D. B. (2010). Household responses to pandemic (H1N1) 2009related school closures, Perth, Western Australia. Emerging infectious diseases, $16(2), 205$. https://doi.org/10.3201/eid1602.091372

Ferguson, N. M., Cummings, D. A., Fraser, C., Cajka, J. C., Cooley, P. C., \& Burke, D. S. (2006). Strategies for mitigating an influenza pandemic. Nature, 442(7101), 448-452. https://doi.org/10.1038/nature04795

Germann, T. C., Kadau, K., Longini, I. M., \& Macken, C. A. (2006). Mitigation strategies for pandemic influenza in the United States. Proceedings of the National Academy of Sciences, 103(15), 5935-5940. https://doi.org/10.1073/pnas.0601266103

Han, Q., Lin, Q., Jin, S., \& You, L. (2020). Coronavirus 2019-nCoV: A brief perspective from the front line. Journal of Infection, 80(4), 373-377. https://doi.org/10.1016/j.jinf.2020.02.010

Johnson, A. J., Moore, Z. S., Edelson, P. J., Kinnane, L., Davies, M., Shay, D. K., Balish, A., McCarron, M., Blanton, L., Finelli, L., Averhoff, F., Bresee, J., Engel, J., \& Averhoff, F. (2008). Household responses to school closure resulting from outbreak of influenza B, North Carolina. Emerging infectious diseases, 14(7), 1024. https://doi.org/10.3201/eid1407.080096

Kawaguchi, R., Miyazono, M., Noda, T., Takayama, Y., Sasai, Y., \& Iso, H. (2009). Influenza (H1N1) 2009 outbreak and school closure, Osaka Prefecture, Japan. Emerging infectious diseases, 15(10), 1685. https://doi.org/10.3201/eid1510.091029

$\mathrm{MOH}$ (Ministry of Health). (2020). Retrieved on 13 April 2020 from http://site.moh.ps/

Mulenga, E. M., \& Marbán, J. M. (2020). Is COVID-19 the Gateway for Digital Learning in Mathematics Education?. Contemporary Educational Technology, 12(2), ep269. https://doi.org/10.30935/cedtech/7949

Sadique, M. Z., Adams, E. J., \& Edmunds, W. J. (2008). Estimating the costs of school closure for mitigating an influenza pandemic. BMC public health, 8(1), 135. https://doi.org/10.1186/1471-2458-8-135

Toquero, C. M. (2020). Challenges and Opportunities for Higher Education amid the COVID-19 Pandemic: The Philippine Context. Pedagogical Research, 5(4), em0063. https://doi.org/10.29333/pr/7947

Viechtbauer, W., Smits, L., Kotz, D., Budé, L., Spigt, M., Serroyen, J., \& Crutzen, R. (2015). A simple formula for the calculation of sample size in pilot studies. Journal of clinical epidemiology, 68(11), 1375-1379. https://doi.org/10.1016/j.jclinepi.2015.04.014

Viner, R. M., Russell, S. J., Croker, H., Packer, J., Ward, J., Stansfield, C., Mytoon, O., Bonell, c. \& Booy, R. (2020). School closure and management practices during coronavirus outbreaks including COVID-19: a rapid systematic review. The Lancet Child \& Adolescent Health. https://doi.org/10.1016/S2352-4642(20)30095-X

WHO (World Health Organization). (2020). Coronavirus disease (COVID-19) outbreak situation. Retrieved on 13 April 2020 from https://www.who.int/emergencies/diseases/novel-coronavirus-2019 